\title{
The Dead in the Land: Encounters with Bodies, Bones, and Ghosts in Northwestern Cambodia
}

\section{LISA J. ARENSEN}

This article explores one Cambodian village's engagement with the remains of the dead encountered during postwar resettlement. For Khmer Buddhists, the correct material transformation of the bodies of the dead is critical, but these processes were often disrupted in Cambodia's recent troubled past. This article describes the subsequent ramifications of these interrupted processes for both the living and the dead in Reaksmei Songha village in northwestern Battambang. Various residents had encountered the bones of the war dead, and some described sightings of ghosts. Kinship played a vital role in villagers' responses to unearthed bones. However, residents tended to downplay the impact of these remains and their ghostly counterparts, possibly because of their own affective identification with the plight of the dead.

T ${ }^{\text {Hen Yei moon and Ta Haim }}{ }^{1}$ decided to move to their current house plot, they filled a truck with earth from their farm, the site of a mass grave from the harsh years of Democratic Kampuchea. When the earth was poured out to build up the new foundation, an entire skeleton tumbled free along with it, unknowingly transported whole from the farm. "It was like this," Yei said to me, tracing the outline of the skeleton upon a bamboo bed. "Head, legs, arms, all kept together," she explained. The elderly couple had taken the bones and thrown them into the pond to "make them cool." Yei explained that she thought coolness would help the bones be at ease. The spirit, she insisted, had "disappeared already"; this treatment was expressly for the bones.

Such accounts were not uncommon in Reaksmei Songha, a village in Ratanak Mondul district in the province of Battambang. The village where I conducted my ethnographic research in 2009 had been the site of a labor camp under Democratic Kampuchea, and then abandoned during the war years. Located upon the frontlines of the war, the land around the village was heavily mined and slowly returned to secondary forest. Resettlement began after the 1996 surrender of Khmer Rouge forces in the area, at which point land was allotted to those willing to risk occupancy on possibly mined terrain. The first postwar settlers were primarily former soldiers and residents of nearby resettlement sites, a mixed population of internally displaced people and

Lisa J. Arensen (larensen@fieldstudies.org) is Resident Lecturer in the Center for Mekong Studies at The School for Field Studies.

${ }^{1}$ All research subjects' names have been changed, but I have followed the customary Khmer practice of using age-specific pronouns before names. "Yei" and "Ta" are Khmer pronouns used to refer to an elderly woman and an elderly man, respectively. 
returning refugees. Area resettlement was driven by need, forged by hope, and fraught with physical risk and material dangers. Food security and the prospect of acquiring land rights required settlers' active engagement with a forested landscape strewn with the remnants of war and unsettling traces of the past.

These postwar settlers often encountered human bones scattered on or under the surface of the land. Most of these bones were the remains of victims of the war years or of the ravages of Democratic Kampuchea. This article examines the complex engagements that the living inhabitants of the landscape had with these remains. It begins with a discussion of the customary treatment of the dead by Khmer Buddhists and the massive disruption of these rites and rituals in the troubled past. I go on to consider the results of these improper transformations, the human bones scattered across the landscape at the end of the war, and discuss how area residents engaged with such troubling remains. I then turn to a discussion of the affective presence of these bones as ghosts, distinguishing between longstanding conceptions of wild ghosts and the specific emergence of these historical ghosts of the war dead. Lastly, I analyze the divergent ways in which the living engaged with these various aspects of the grievous dead.

\section{Proper Transformations}

The word "kmaoch" in Khmer refers to both corpses and ghosts, and is also used as an adjective for the term "deceased." The term thus encompasses both material and immaterial aspects of the dead. Kmaoch can mean the wholly material physical bodies of the dead, and in residents' accounts of the troubled past the deterioration of corpses was sometimes spoken of unstintingly-corpses rotted, their fat came out, their blood stank, and animals ate their dead flesh. When a corpse had been reduced to its bones, it was referred to by those bones alone, chiung. Kmaoch could also refer to the less material substance of a ghost, unsettled and unsettling spirits of the dead that usually appeared in human form.

The "ambivalent agency" of human bones, which are experienced as both subjects and objects, yet never wholly fit within either categorization, has been a recent focus of the anthropologists and archaeologists of the Bones Collective (Krmpotich, Fontein, and Harries 2010). In a series of seminars and articles, these theorists have convincingly argued that the impact and effect of human bones upon living persons is "not confined to questions about the representation of the past, or indeed their 'symbolic efficacy' ... but also has something to do with their 'emotive materiality' as human substances and their 'affective presence' as dead persons” (Fontein 2010, 431; see also Filippucci 2004; Filippucci et al. 2012; Fontein 2011; Hallam 2010; Harries 2010). This article will explore the relevance of these categories of emotive materiality and affective presence for the human remains encountered in Reaksmei Songha.

In his recent work on the Zimbabwean politics of death, Joost Fontein $(2010,437)$ has argued that attention must be paid to the material aspects of the culturally specific rites and processes of physical transformation "through which the living become properly dead." I will illustrate that for Khmer Buddhists as well, the significance and impact of bodies and bones upon the living are inextricably linked with the material transformations that change dead bodies to bones. 
In Khmer Buddhist cosmology, the fate of the spirit of the deceased is perceived as bound up in multiple and often overlapping factors, including the manner of death, ${ }^{2}$ the cumulative karmic merit or demerit of the deceased, and the physical treatment of the corpse. Funerary rites involve a complex assemblage of elements, but my interest here is in the physical treatment of the body of the deceased. Such rites often involve processions transporting the dead body from the home to a crematorium in the sacred confines of a wat's grounds. ${ }^{3}$ The proper transformation of the dead body entails its cremation. This physical transformation or reduction of fleshly body to bone is sponsored by and enacted in the presence of kin, who are in many cases expected to light the funeral pyre. After cremation, kin pick out the remaining fragments of bones from the ashes and place them in white cloth bags, which are either placed in urns and taken to stupas in temple compounds, or placed in ancestral shrines in the home (Harris 2005). Offerings and prayers are made before these emplaced remains at the appropriate Buddhist festivals. In short, for the Khmer Buddhist, a dead body is meant to be reduced to burnt bones. This material transformation of bodily substances is an integral component of the metaphysical freeing of the dead person's spirit, which then progresses to various levels of heaven, hell, or rebirth. However, the fact that kin keep and tend cremated bones and intercede with the dead at the site of their bones implies that these departed spirits are still somehow linked to their material remains.

Heonik Kwon's $(2006,2008)$ work on war ghosts in Vietnam reveals an array of similar conceptions about the manner of death and the import of the treatment of human remains. In his discussion of the civilian massacre at Ha My, Kwon (2006) notes that the Korean marines responsible for the killings bulldozed the bodies of the dead in an attempt to destroy evidence. The victims' surviving kin perceived this destruction of bodies as even more inhumane and distressing than the initial executions. The physical treatment and consequent material state of these human remains was regarded as having consequences far beyond the grief and horror experienced by their kin, destroying the dead souls' chances to be transformed into ancestors and condemning them to a sorrowful afterlife as wandering ghosts. Khmer Buddhists share the understanding that the improper treatment of human remains prevents the transformation of a body's spirit, trapping it instead in this world as a ghost. A much-publicized discussion of such matters in Cambodia revolved around the 2002 removal of a cluster of 300 human skulls that had been fixed upon a crude map of Cambodia on one of the walls of the Tuol Sleng genocide museum. Since 2001, King Norodom Sihanouk lobbied for the cremation of the skulls and all human remains of Khmer Rouge victims still on display in various memorialized killing fields, in order that the spirits of the victims could find rest (Cougill 2007).

\footnotetext{
${ }^{2}$ As in other Southeast Asian Buddhist cosmologies, deaths from violence are regarded as particularly grievous and inauspicious (Hughes 2006).

${ }^{3}$ Some families do not use the wat crematoriums, but rather construct a cremation pyre at their homes and sponsor the monks to perform funerary rites there instead (Marston 2006). My Khmer acquaintances contended that this expensive practice was limited to the rich and was done to ensure that the remains of dead kin would not mix or mingle with the remains of unknown others in the crematorium.
} 
Not all Cambodian Buddhists practice cremation. Families with Chinese heritage bury their dead in raised mounds that they decorate with headstones or white strips of grave cloth. The wat compound in Reaksmei Songha village, like many others, contained both a site for stupas in front of the wat and a Chinese-style gravesite back by the wat reservoir. ${ }^{4}$ I was told that once in a great while, humans wandering at night across these gravesites would stumble upon ghost-villages, where the ghosts were carrying out lives full of the same material goings on as in the realm of the living-grooming each other's heads for lice, growing rice, cooking over fires, and keeping livestock. These domesticated ghosts ignored the humans trespassing in their realm.

In Cambodia's recent troubled past, these customary acts of cremation or burial often failed to occur. For Cambodia, as in neighboring Vietnam, it is against a "historical landscape of generalized violence and mass displacement that people perceive today the presence of grievous ghosts of war" (Kwon 2008, 15) and encounter the uncremated remains of the dead. A variety of postwar settlers discovered such remains in Reaksmei Songha village, yet because of their own displacement, for most inhabitants these remains were unknown and unidentifiable, the remains of strangers. The very presence of such remains as well as their physical state stemmed from the shifting contexts of war-related violence and the state-sanctioned terror of Democratic Kampuchea (DK).

\section{Bodies Out of Place}

Customary treatment of the dead had been interrupted during the long years of conflict, and forbidden under Democratic Kampuchea. In residents' accounts of these periods, the dead featured repeatedly, discussed largely in their corporeal form, as corpses. The lack of correct treatment of human remains was a recurring theme.

The abandonment of corpses was often discussed in reference to wartime. During the years of fighting that preceded and followed the DK regime, concerns about tending the remains of the dead were secondary to surviving the perilous present. Numerous villagers described sleeping on graves or fleeing past corpses. The ground was full of the smell of rotting bodies during the war, my host mother said, from dead bodies left along the sides of the roads. It was abnormal, she said, unnatural. Many bodies were discarded, her husband added, as there was "no one to think about that matter." Others spoke of leaving the bodies of dead kin during the fighting. When I asked one elderly woman if people were buried rather than cremated during the civil war before the DK regime, she stated:

There wasn't time. In a big war, who of us has time? ... Shells come thung thung thung!

Me: So you had to leave people behind?

First woman: We had to leave bodies behind. [My husband] was running, I was running, he ran, the bodies [were left] back there.

${ }^{4}$ I have limited this discussion to Buddhist practice, as the subjects of this study were almost entirely Buddhist. The Muslim Cham and various indigenous highland groups in Cambodia also bury their dead. 
The neglect of corpses not only resulted from flight but also reflected the massive displacement of kin during the war years. If one died away from one's kin, one's body was unlikely to be properly cared for. The village chief once described a dangerous journey he and his brother-in-law had made in the last years of the war, traveling along remote forest trails to the ruby mines in Pailin. There were long lines of people in the forest, he recounted, and some stepped upon landmines the Khmer Rouge had planted along the trails. The bodies of those killed in such a fashion were simply tossed into the forest on the sides of the trails. When I asked why the bodies were treated in this manner, he replied simply: "We did not know who they were." The single exception I heard to this neglect of the bodies of non-kinsmen was an account by a former soldier, who described his unit's efforts to cremate the maimed bodies of fellow soldiers.

Cremation rites were forbidden by the Khmer Rouge as part of its ban on Buddhist practice. During DK, the many who died of illness or starvation "received at best hurried burials," sometimes singly or in mass graves, whereas the bodies of those executed in killing fields or the forests were often simply "left to rot" (Edwards 2008, 158). One group of elders compared the treatment of human remains by the Khmer Rouge to the treatment of animals. This was an early interview and one where I was particularly slow to follow my interlocutors:

First woman: They killed people like dogs and cats.

Me: Dogs and cats? [The elders present all laugh at me.]

Second woman: When dogs and cats die in the forest, no one does anything. When they die, they're dead.... During the war, when people died we compared it to dogs and cats. Because there was no one to do ceremonies.

Man: She's never seen anyone killed in America. In this country, they killed people like dogs and cats.

Burial presented the possibility of wild animals interfering with corpses, a matter people spoke of with horror. Himm Sokreaksa's (2003) memoir describes a mass execution in the forest by Khmer Rouge cadre, which left him the sole survivor of his family. He gives an extended account of the three nights he spent hiding in the forest, returning repeatedly to the mass grave and making futile efforts to keep animals from the bodies. When he returned with an uncle after the war to collect the bones, they were unable to distinguish the bones of their kin: "Animals had dug into the loose earth; the ground was disturbed and bones were scattered all around" (Himm 2003, 100). Identifying the bones of their kin was impossible, and they ended up cremating every human bone they could find. A similar travesty was said to have happened in Reaksmei Songha village. One of the monks was killed at the wat, my host mother Ming Ni told me grimly, and a wild pig had eaten his body. Tales like this indexed the terror of the period — a wild creature was able to freely enter a defiled sacred space and devour the body of a holy man that should have been cremated. In those terror-filled times, citizens could no longer enact the Buddhist rites that would ensure safe transformation from the world of the living to that of the dead.

Employing bodies in particular ways and interfering with customary religious means of dealing with dead bodies was a deliberate feature of political violence by the Khmer Rouge, linked to other mechanisms of terror and suppression. Chris Ballard (2002, 13) has asked of regimes that employ terror, "How does death—or, more accurately, the 
specific terror of an unfamiliar, unexpected, or violent death-come to inhabit a landscape? How is the land itself marked, manipulated, and deployed in the orchestration of terror?" In the context of the Khmer Rouge, some of the answers to this question lie in the alternate display or disappearance of the bodies of the dead.

The first wave of executions under Democratic Kampuchea in Year Zero (1975) was comprised largely of state soldiers, and many of these executions occurred during the forced mass evacuations of urban areas (cf. Pin 1987; Someth 1986). During these evacuations, soldiers were identified or called to identify themselves. Several elders told me that announcements were made spuriously inviting soldiers to make themselves known so that they could be reorganized and welcome the return of the exiled King Sihanouk. Soldiers who identified themselves were executed, sometimes en masse. Many of these corpses were deliberately left along the edges of roads in full view of the town-dwellers and refugees thronging the roads. Yei Moon recalled seeing such bodies as she was marched along the national highway out of Pailin. She was riding in a pushcart with a newborn infant when she saw the bloated bodies of the dead soldiers, and she did not recognize them as men. She turned to her husband and said aloud, "Look at all those dead pigs on the side of the road," only to be quickly hushed, as he whispered urgently to her that she was gazing not upon pigs but men. One was supposed to see those dead, but not to comment upon them. They were a visible rotting menace that people had to pass by on their way to the new society, and avoiding a similar fate depended in part upon becoming mute.

However, in contrast to these menacing displays, a great deal of killing also took place out of sight. In the mass cooperatives, although physical punishment and torture of "miscreants" were routinely carried out in front of the cooperative members, it is clear that actual executions (and the prolonged torture that sometimes preceded them) most often took place outside of the public eye, with victims being led away into uninhabited bush or sites now commonly referred to as killing fields (Him 2000; Ponchaud 1989). Despite the ubiquitous use of threats and metaphors of violence and execution by cadres, actual killings often went unannounced and remained shrouded in silence. Instead, when people were taken away to be killed, their fate was often only referred to in euphemistic terms, a particularly common one being that a victim was being taken away "to be educated by Angkar" (Locard 2004).

According to village elders, killing enemies of the revolution in isolated parts of the district was also a common Khmer Rouge practice during the civil war of the 1970s. One elder argued that such killings before the overthrow of the Lon Nol government were deliberately covert so that local collaborators would not realize the true nature of the revolutionary movement. Yet Yei Moon argued that even these secret killings sometimes involved an element of display. Corpses were dealt with by those who carried out executions, and buried in pits or shallow graves, she said, but this "covering up" of the dead was often left half done:

Those Pol Pot ones buried them. They just half-buried [corpses]—arms still left out, legs left out... They took all the clothing, only the body remained. Furthermore, they made you dig your own grave. They struck [you after you] dug it yourself! Once you had dug it, they felled you. Such were the Red Khmer. 
That at least part of such practices was common is evidenced by the DK-era counterslogan people used to mock a regime directive: "Be masters of your own destiny! Die and bury yourself!" (Locard 2004). ${ }^{5}$ Yei Moon's description of these half-burials, of a body half in and half out of the earth, made a vivid impression upon me-I at first interpreted these hasty burials as merely a show of indifference to the fate of the dead but later realized that half-burial acts as another kind of menacing display. A half-buried corpse indicated an execution had taken place, but such killings were unable to be openly discussed in safety in that period's climate of growing menace and distrust. Such corpses were not hidden, but the killings preceding them took place in secret, and the fate of these bodies was shrouded in silence. ${ }^{6}$

However, as noted above, these practices continued under Democratic Kampuchea, where there was no reason for such secrecy. Moreover, as numerous accounts and memoirs show, although these executions went undiscussed, few actual attempts were made to cover the fact of the killings. Instead, cadres routinely engaged in such practices as stripping the dead and bringing back their clothing for redistribution among the living (Hinton 2008). This article does not attempt to deal with the alternating subtleties and blatancies of psychological and physical terror employed by the Khmer Rouge. ${ }^{7}$ The point I wish to make is that in a great many cases people died and their bodies were disposed of away from their kin. This was not only the case for executions. The numerous sick who perished in the "clinics" of Democratic Kampuchea, which generally lacked medicine and qualified medical personnel, were often buried in shallow mass graves nearby, as in the case of the clinic in Reaksmei Songha village. Furthermore, as a consequence of the dissolution of families into age-segregated camps, many family members were not present for the death or disposal of the bodies of their kin during DK. Many only learned that family members had died months after the fact (cf. Someth 1986).

As a result of these practices, a great many survivors of the Khmer Rouge regime had no idea of the location of the bodies of their dead kin. Numerous area families spoke of the missing corpses of kin. Yei Moon, for example, had not been present for the killing or burial of her first husband, which took place in 1971 as the Khmer Rouge were gradually expanding their control over the area. She had searched for his grave to no avail. Others told her he had been buried near the path between their village and the neighboring village, a three-kilometer stretch, but she found no trace of his remains. The family did not know at first that he had been killed, she said, simply that he was missing. You could not make inquiries after the missing at that time, she emphasized, or the Khmer Rouge would kill your remaining family members for casting suspicion on them.

Some families had managed to secure permission to bury their dead. Yet even this did not guarantee that the bodies could be successfully located later. Several families told me that they could not find the graves of their dead when they were finally able to search for them. Graves were effaced by the altered landscapes of the DK and subsequent regimes. One elder's young daughter had starved to death during their family's first

${ }^{5}$ I have retranslated the Khmer phrase Locard cites here.

${ }^{6}$ One of my anonymous reviewers astutely pointed out that to half-bury a body may not have been merely a threat to the living or an act of indifference but also a deliberate act of desecration that prevented the proper transformation of the dead soul, in a sense removing the future of the dead. ${ }^{7}$ Alexander Hinton's $(1998,2005)$ work deals extensively with these topics. 
labor camp placement near Kampiung Poi reservoir. The man and his wife were permitted to bury her. But, after the war, they were unable to locate the grave. After their relocation to another cooperative, the cadres had ordered the people to grow rice over the area and build rice field dykes, rendering the grave's location unrecognizable.

Another elderly woman recalled burying her husband herself in the forest. There were no ceremonies then, she said, nothing to wrap bodies with, not even grass mats. She had buried him herself, "like an animal," without any of the appropriate rituals. "At that time," she recalled, one "buried [the dead] in the night, and in a hurry." She had come back exhausted, in the dark, leaving the grave unmarked. Tragically, the once forested area had been turned into cultivated fields, and she did not know where to find his grave.

In addition to these missing bodies, abandoned bodies also littered the remembered landscape of war stories. One elder described the countryside at the end of the DK regime as being like the "land of the dead," empty and forlorn, but one of his stories also vividly described the dead in the land. After the Vietnamese invasion in 1979, he and a group of companions traveled on foot back to their home towns, sleeping on the national highways "like dogs," and cooking wherever they found water to boil the rice. Near a former front line where the two sides "had fought strongly," his group was thirsty and saw a thigh-high field of rice. It was a lush green color, so they knew there was water present, and they went down from the road and entered the field, and found it full of corpses. The field was dense with their bodies, men and women in Khmer Rouge uniforms, lying at the site of their defeat at the hands of the Vietnamese with "no one to take them anywhere." When he had seen that green rice he had thought there would be water, the elder mused, and there was, but "water full of corpses." The dead lay rotting in the lush field, their bodies, discarded and unclaimed, making the land fertile. This state of affairs echoed one of the Khmer Rouge threats before its defeat-to kill enemies of the regime and use their bodies as fertilizer (Locard 2004), a threat that had ironically been turned upon their own dead bodies.

\section{Finding THE Bones}

By the time Reaksmei Songha village was resettled, the corpses in the landscape had been largely reduced to bones, which were sometimes accompanied by remnants of their possessions. Various bones were encountered by the settler families. Skulls and heads of long hair lay along the road to Mount Anong. The skeletal remains of a dead woodcutter were found in the forest, his knife lying near his bones. Yei Moon's farmland had been the burial site of the dead from the DK clinic, and bones were found in far greater numbers on her land. When digging in the fields, my host family had uncovered bones, teeth, cooking pots, rotting clothing, blankets, and hammocks.

What did they do when they found such things? I asked.

"We didn't do anything," Yei Moon said. "We covered them back up."

Her daughter, Ming Ni, ${ }^{8}$ added: "You take parents' bones to the wat. We don't take others' bones there. These were the bones of strangers, not our relatives."

\footnotetext{
"Ming" is a Khmer pronoun that means "aunt."
} 
As noted previously, many area families had dead kin whose remains could not be located. Bones were regarded as belonging to kin, regardless of their location. If families could identify the bones of their kin, they were permitted to remove or tend to them. However, I heard only two accounts of families returning and finding the remains of their dead in Reaksmei Songha.

An unknown family had come several years prior to 2009 seeking the bones of their dead parents. They came in two cars, Ming Ni and Yei Moon recalled, packed full. They were a wealthy family based in Battambang, with relatives who had immigrated to America. One of the siblings had buried her parents in the field behind the clinic, and put a stone to remember the place. They searched Yei's land for the bones, dug until "they were tired to death," and took the bones away with them for cremation at their family wat in Battambang city.

One other family had also been able to locate the place where their father had been shot. They found their way to his remains through their memory of landscape referents that had remained unchanged, a line of hills and the rural road. Their father's bones lay on Bu Klang's land. ${ }^{9} \mathrm{Bu}$ Klang was a farmer and a former Khmer Rouge soldier. “They came and asked if I had seen any bones," Bu Klang said, "and I had, I had seen a skull." He had left the skeletal remains untouched and guided the family to them. This family dealt with the kin-bones differently, revealing their Sino-Khmer heritage. Instead of removing the bones, they gathered them up into a single pile and built a cement grave mound over the site. They returned each Buddhist New Year to burn incense to their father's spirit, $\mathrm{Bu}$ Klang said, and because they cared for the remains, he had "never seen [the bones' spirit] haunt," even though he and his children slept nearby.

$\mathrm{Bu}$ Klang himself had gone looking for the bones of a cousin among the many graves on Yei Moon's land. It was said his cousin had been buried near the tamarind tree, $\mathrm{Bu}$ Klang said, but he could not ascertain where the body was. Some of the bones my host family had unearthed and covered back up might well have belonged to his kinsman, but he had not been present to inscribe the location of the grave into his memory, and now, stripped of their flesh, reduced to mere bone, the remains were indistinguishable as specific persons. The inability to locate and tend to the bones of their dead comprised an ongoing source of sorrow for many area residents. Instead of finding their kin, various residents encountered the bones of strangers. ${ }^{10}$

Although respecting them as human substances and recognizing their pitiful condition as deteriorating objects, those who found human bones could do little more than leave them undisturbed. The presence of these bones was noted as temporally limited by some. Yei Moon, for example, insisted that the bones from the mass graves on her land were "all rotten" now. "Now it's only earth," she told me firmly when I asked whether there were still bones present_- "there's grass over the place.... The land is now all overgrown." Although this process was self-evidently not happening at the rate Yei Moon might have hoped, as organic materials, the distressing bones would eventually

\footnotetext{
9"Bu" is a Khmer pronoun that means "uncle."

${ }^{10}$ See May Ebihara’s (1971) classic ethnography for a discussion of the general suspicion surrounding strangers. However, fictive kinship bonds are often forged between nonbiological kin in Cambodia (Davis 2008). These claims are often strengthened through commensality, the sharing of food (Zucker 2013).
} 
dissolve beyond recognition, mingling and mixing with the material substances that surrounded them.

However, the bones of the dead were not only troubling via their material presence and condition. They also manifested an affective presence as dead persons, and it is to this that I now turn. How did villagers experience this affective presence, which John Harries $(2010,414)$ has termed "the presence and absence of those who have been but are no longer?" I will demonstrate that this question of affective presence was bound up in residents' accounts of encountering ghosts, sometimes threatening but always grievous, trapped in the landscape by the improper transformation of their physical remains.

\section{Ghosts of the Violent Past}

Wartime accounts of leaving behind or moving through the dead did not contain ghosts. Instead, the fears of the living were concentrated on the pressing threats to their own continued survival-falling shells, armed troops of various factions, the mined roads and fields. But when the war was over and resettlement began, ghosts comprised one of the many threats present in the landscape.

An initially confusing array of ghosts was discussed in the village. Ming Ni came into my room my first night in the village and reoriented my grass sleeping mat. You cannot sleep facing west, she said. The ghosts will come. West was the direction of death, and night, when we lay upon our mats, was the time when ghosts walked. There is something of a renaissance in ghost stories underway in contemporary Cambodian popular culture. Accounts of malicious ghosts, predominately female, who haunt and kill the living are myriad in horror films, the dominant genre of contemporary Khmer-produced films. They also feature in karaoke music videos and make ubiquitous appearances in serialized television shows from Cambodia, China, and Thailand. However, there have always been a variety of ghosts in the Khmer imaginary, and they take a variety of forms. Without becoming embroiled in a taxonomy of ghosts, I will briefly mention some general characteristics of ghosts that were germane for ghost narratives in my area. Like other kinds of spirits, ghosts were said to frequent forests and roost in trees. Before the forests were cleared, I was told, the ghosts often made their presence known to the settlers by tossing small stones and breaking branches, announcing their uncanny presence by making the sounds an embodied person would make moving across the same terrain. Ghosts posed the greatest peril for those who were alone or located in isolated areas.

Human settlement in the forest was thought to partially roust out these ghosts. One villager said to me: "The Khmer enter the forests and chase out the ghosts" [khmai johl prey nung denh kmaoc]. ${ }^{11}$ The following excerpt of a discussion with the family of a traditional spirit healer displays a common local interpretation of the departure of this sort of ghost:

\section{Me: Are there any ghosts left? \\ Healer: No, that's very rare now.}

\footnotetext{
${ }^{11}$ When asked to explain, the villager and his companions told me there was an old expression that I have translated as follows: The Chinese chase out the Khmer, the Khmer chase out the ghosts, and the rich chase out the poor until the poor flee into the forest.
} 
Son: It seems quiet now.

Me: Why?

Healer: So many people are living here now that the evil fled. It's clear and open [srolah].

Me: If it is clear and open, there are no more ghosts?

Daughter: When it was quiet, there were many ghosts.

Healer: Yes, many ghosts.

Son: When there were big trees, thick forest, they lived here.

Wife: They were laughing, happily. They made people sicken and die. Now they are disgusted by people's feces and urine, so they went away. Before, people couldn't live here.

Son: I saw the flying ghost-fire floating at the cliffs.... Forty to fifty fires per night.

Wife: They flew near the mountains.

The ghosts discussed above are known as pri'e, a particular type of evil female ghostspirit, who villagers claimed are "horrible when they haunt." ${ }^{2}$ Pri'e were said to inhabit the area by a variety of people. The presence of the prie was deduced not only through cases of ghost-sickness among the early settlers but also by sightings of blue globes of ghost-fire flying along the tops of the forest at night. Although the healer's family argued that these ghosts had largely fled, a number of other settlers said that prie still dwelled in trees on the edges of the forested mountains. There were varying levels of concern about the threat the pri'e posed to villagers.

I gradually began to distinguish between accounts of these forest-dwelling ghosts, which, like other sorts of wild spirits, were associated with the wilderness, and accounts of ghosts who were specifically linked to the presence of human bones embedded in the landscape from the war years and the era of Democratic Kampuchea. These ghosts were linked to the fate of their remains and had concrete identities as persons who had once lived and died in the area. Yet they were strangers to those who encountered them.

These war ghosts were described as being "like humans" in form and behavior. They lingered near the sites of their remains, such as the graves on Yei Moon's land. In a spectacularly unconsidered development, an NGO had built the local primary school directly adjacent to the field of graves on Yei's land, and for a period there had been haunting episodes around the school grounds. This did not discourage parents from sending their offspring to the school in droves, although this was presumably because most encounters with ghosts occur at night. Ming Ni described one of these hauntings to me in detail. The ghosts fell upon a man walking by the school one night. They made the sandy field in front of the school appear to be a pool of water, and he began to swim across it to escape them. When they vanished and the illusion dissipated, he found himself "swimming on the land," scratched and bleeding. However, despite a few accounts like this, the ghosts of the mass graves were described first and foremost as hungry. Yei Moon, who had lived on the land at the time, saw the ghosts night after night-but her descriptions were not filled with terror but rather almost prosaic. The

${ }^{12}$ Such ghosts are often thought be the troubled spirits of women who died in childbirth (cf. Ang 1986). 
ghosts walked in the night, searching for food. She saw their cooking fires beneath the trees one night in cold season. On another occasion, she saw some of them pass by the house, male figures dressed in white, and she mistook them for her sons.

These ghosts are superficially similar to the traditional Khmer concept of the pretas, the hungry ghosts. Pretas are the incarnations of humans who committed venial sins and have been sent to hell, where they are forced to ceaselessly forage for food in disgusting waste, food that never sates their hunger but instead transforms into foulness upon their tongues (Davis 2016). The king of hell allows the pretas to return to the earth during the fifteen-day celebration of Pchum Ben, when they are fed by the living at Buddhist wats across Cambodia (Davis 2016). The pretas often manifest themselves as tall, stretched, emaciated forms with tiny, puckered mouths. However, despite their hunger, the ghosts of the Pol Pot dead, as the villagers termed them, were not pretas. They were not in hell but rather trapped in the present. They had died starving, and they were still starving. Like the living, they could light fires, forage, and cook food. They also wept, and were considered piteous.

The primary ghosts encountered in the neighboring village, on the other hand, were said to be dead Khmer Rouge struck by artillery shells during the war years that followed the DK regime. The remains of their possessions had been used to diagnose the identity of these ghosts. Blast holes had been found by still-slung rotting hammocks, abandoned mosquito nets, and Khmer Rouge tire sandals. Just like the living, the ghosts in the landscape were intermingled in their allegiances, some victims of the DK regime, others fighters killed in battle. Area residents had fought for various and often multiple factions during the war years, and nearly every male resident over forty had been a soldier at one time or another. Villagers did not seem to distinguish between the ghosts of civilians or soldiers - the ghosts' common deaths through violent means seemed more salient.

These war ghosts were not uniformly considered harmful by village residents. Some people claimed to have seen ghosts but had not been terrified or threatened by them. Yei Moon was a prime example of this category of person, and several people informed me that ghosts could not harm you if you did not fear them. Bu Klang, the former Khmer Rouge soldier, was also unconcerned about ghosts. ${ }^{13}$ Over to the west of his farm, he said, others said there were haunting-ghosts, but he had never encountered one. He pondered for a minute, then said, "One night I was walking by the spring and saw the head of a person in a tree. Maybe that was a ghost. In a hole.” The Khmer Rouge had encamped at the spring, and fought there, he said thoughtfully. He had seen the head, but it "did not haunt" him; it "did not do anything."

Nonetheless, whether they feared them or not, most area residents considered the presence of ghosts either piteous or undesirable. Ghosts were spirits out of placetrapped by the manner of their deaths and the state of their remains. Villagers' efforts to appease or remove these ghostly presences were varied. Many turned to Buddhism-it is common practice to bring monks to haunted sites to address ghost problems in Cambodia. ${ }^{14}$ In a rather less orthodox move, rather than bringing monks to the ghosts, Yei Moon

\footnotetext{
${ }^{13}$ It is possible that his Khmer Rouge background explains his lack of fear, but this may also have been due to his familiarity with death, like many other former soldiers I interviewed.

${ }^{14}$ There is a Khmer game in the tradition of rock-paper-scissors that has three characters: a monk, a ghost, and an unmarried young woman. The ghost conquers the unmarried young woman, the
} 
claimed to have summoned the ghosts of the mass graves on her land to the wat. Each week, as she headed to the wat on the day of penance, she related, she would stand on the corner of her land and call into the wind, calling the ghosts to follow her and enter the wat. Eventually, she said, they came, and had not returned. Why had they stayed in the wat, I inquired. "They wanted to practice dharma," she said, with a trace of a smile. In another case, one of the hungry ghosts manifested himself in a dream to a local man, begging to be fed. ${ }^{15}$ When he awoke, the man took food to the wat and asked the monks to bless and offer it to the ghost, and the ghost, presumably satisfied, had not reappeared in the man's dreams. These accounts reveal that the sacred space of the wat, the site where transactions between the living and the dead are meant to occur, was thought to offer sanctuary and even respite for the uneasy dead.

Other family members had invoked the assistance of territorial guardian spirits. Despite Yei Moon's claim to have rid the mass gravesite of ghosts, when her granddaughter and her husband, Sopiap and Lem, began to erect a house, they took pains to ensure that no ghosts would disturb the process. The building site was directly adjacent to Yei's land. If ghosts inhabit a portion of land, the family explained, they will not permit humans to live safely upon it. When the house foundation was laid, the couple made an offering specifically requesting that any lingering ghosts from the Pol Pot era leave the place. The ghosts were asked to go to a place that has happiness and peace, Lem explained to me. But the cosmological terrain was not left empty - when the ghosts were asked to leave, a guardian spirit was simultaneously invited to inhabit the house plot and protect the family. The guardians can protect you from ghosts, Lem explained. This invitation was given material substance. When the house was built, a new prea phum (a spirit house on a pillar) was erected for the guardian in front of the house, with votive offerings placed upon it. Both the human family and the territorial spirit were housed in a way that ghosts could not be. The extended family also sponsored a blessing of the house by the monks of Handsome village's wat.

Although the presence and condition of these ghosts of the violent past were directly linked to the presence and condition of their bones, only kin could tend to these bones. Therefore, as these stories illustrate, residents generally responded to unknown bones via their affective presence as ghosts rather than via their troubling material substance. Yei Moon, for example, solved the problem of the school hauntings by calling the ghosts to the wat. She did not gather up the bones of the war dead strewn across her land and take them to the wat. Sopiap and Lem likewise did not engage with the physical remains of the war dead. Their primary concern was to ask the ghosts themselves to go elsewhere.

\section{The Unsettling Dead}

Ewa Dománska (2005) has discussed the status of human remains as objects of mourning and as corpus delicti, the material evidence of a crime. The bones villagers encountered

unmarried young woman conquers the monk, and the monk conquers the ghost. For further reading on Khmer Buddhist monks addressing ghost problems, see Ly (2003) and Ledgerwood (1997).

${ }^{15}$ For a regional comparison, see Erik Mueggler's (2001) work on hungry ghosts in China. 
were material evidence of deaths in the context of war and the ravages of Democratic Kampuchea. Their physical presence acted as concrete and often unwanted reminders that the landscape was not only a forest or a once bountiful region of orchards and farms, but also a place where a variety of people had died, often in violent conditions. The very presence of these human bones displayed the circumstances of the disordered and violent past.

The presence of decaying bones was not only a grim reminder of the troubled past. They also served as reminders of residents' own missing kin, an ongoing source of sorrow and uneasiness for the living. However, these bones not only acted as objects that triggered residents' associations with the past, they also were agentive in other ways. I will now return to the analytical categories of the emotive materiality of bones as human substances and their affective presence as dead persons.

The bones' difference from other nonhuman kinds of war debris was manifest in how differently they were treated. Unlike other material remnants, bones were not intentionally removed, destroyed, or recycled. Villagers attempted to leave them untouched. The bones' ambivalent and intertwined status as objects and subjects is evident here. Like other material remnants of the past, the bones were physical objects that surfaced in the land people sought to clear and cultivate. The bones were discussed as material objects, as organic substances that, like many other material remains, were decaying and rotting. Yet in the case of human bones, their material conditions were recognized as pitiable for their dead human subjects. However, the prospect of changing the physical condition or location of the bones was inextricably linked to the dead subjects' relations to the living. Without claiming them as kin, most village residents felt they could not change the tragic material conditions of these bones.

The scholars of the Bones Collective have suggested that people's “immediate and individualized responses to bones" can fruitfully be understood in reference to matters of kinship and the relatedness formed by sharing landscapes (Krmpotich et al. 2010, 375). In addition, I contend that consideration must be paid to living subjects' relationships to the events and experiences that had resulted in the deaths signified by the bones, a point I will return to shortly. Kinship relations, or the lack of such relations, were clearly a vital influence upon the treatment of bones in Reaksmei Songha village. Questions regarding the identity of the neglected bones appeared insoluble for area residentsstrangers could not tend the bones of non-kin, and many residents could not locate the bodies of their kin, so bones remained where they lay. Yet such bones were not simply material traces of the past but potentially the physical remains of people once known by current area residents. Part of the unsettling nature of these bones was this terrible indeterminacy - buried in mass graves, killed away from kin, or abandoned in battle, the bones were indistinguishable as the living persons they had once been. Such bones could ostensibly be their finders' own missing kin. People simply could not tell.

As Joost Fontein (2010) has demonstrated, the materiality of bones is often intertwined with their affective qualities. In Reaksmei Songha, this affective presence most often manifested itself as sightings of the grievous ghosts of the dead. I have demonstrated that the spirits of the dead are linked to the presence and condition of their bones in the Cambodian context, bones that, ideally, kin keep and tend. Fontein $(2010,437)$ has argued for a movement away from "the notion of composed and contained bodies, towards an understanding of the flows of material that link people, 
artefacts and landscape." In the context of Cambodian Buddhism, certain kinds of material flows and transformations of the dead body were desirable and necessary, whereas others had deeply troubling implications. The untended bones of the dead in Reaksmei Songha, sometimes accompanied by their material possessions, had begun to rot, their substances mingling with the soil, water, and vegetation that surrounded them. If still recognizable as human remains by those who encountered them, these organic processes indicated that the spirit of the dead person was probably trapped in the present and the place, constituting a lingering ghostly presence.

Since little has been written on the subject of the remains of the dead from Cambodia's troubled recent past, ${ }^{16}$ my reading has focused upon such matters in neighboring Vietnam. This reading revealed a marked similarity in the conditions that produced such remains and similar conceptions about neglected bones' affective presence as ghosts. Yet it also illustrated marked differences in practice. A brief discussion of the Vietnamese context will make these similarities and differences apparent.

As in Cambodia, kinship relations extend beyond death and continue between the living and the dead in Vietnam (Marouda 2008). In the ideal transformation of the living to the dead, the dead become ancestral spirits that are venerated and consulted by the living. During the war in Vietnam, the tragically common combination of violent deaths and improper burials resulted in the creation of a great multitude of con $m a$, wandering ghosts. These ghosts remain trapped in a "condition of homelessness and eternal hunger" (Gustafsson 2007, 63), and are alternately regarded as grievous or malevolent, haunting, and troubling the living. Heonik Kwon $(2006,2008)$ has emphasized that the pitiable condition of these war ghosts resides in their forced mobility, their inability to come to rest and reside in the ancestral shrines of their kin. He describes the ubiquitous presence of shrines for wandering ghosts across Vietnam, where offerings are made to temporarily ease the suffering of these grievous souls. He also delineates the enormous growth in citizens' efforts to find the remains of missing kin and to restore the wandering spirits into ancestors. This intense desire to restore the fate of the sorrowful dead has led to a vibrant plethora of commemorative ritual practice, frequently involving the consultation of con ma kin through mediums, as well as a creative restructuring of rites to bring the war ghosts home into ancestral shrines. ${ }^{17}$

The residents of Reaksmei Songha largely lacked this body of commemorative practice, regarding both caring for the wandering dead and the concerted efforts to restore grievous ghostly kin. Instead, villagers often downplayed encounters with bones and sightings of human ghosts. For example, I was told of the ghost of a ploughman killed by an anti-tank mine, which had haunted his neighbors in the hills on the edge of the village for a period. His neighbors told me that the dead man eventually grew weary

\footnotetext{
${ }^{16}$ Two notable exceptions are pieces by Anne Yvonne Gouillou (2012) and Rachel Hughes (2006).

${ }^{17}$ Both Kwon (2006, 2008) and Gustafsson (2007) temporally locate the growth of these practices in Doi Moi, a program of economic liberalization adopted by the Vietnamese state in 1986. Increased economic freedoms were accompanied by a loosening of state control over religious and social life, which corresponded with a massive upsurge in commemorative ritual practices centered upon the grievous dead.
} 
of haunting them and had disappeared, presumably to his next life. They acknowledged his threatening presence but stressed its transience. And I have already noted Yei Moon's emphatic assertion that the bones in the mass graves on her land had already turned to dirt.

Yet I suspect that people discursively downplayed the impact of bones and ghosts in the postwar landscape precisely because of their affective identification with the grievous dead and the harrowing similarities in their past and sometimes present circumstances. For many villagers, these bones and the ghosts that accompanied them were manifestations of what Ewa Dománska $(2005,405)$ has termed the "non-absent past," which she describes as a "past which is somehow still present, which will not go away or, rather, which we cannot rid ourselves of." Layla Renshaw (2010) has discussed the means by which descendants of victims of the Spanish Civil War form affective connections with remains of people from a period of which they have no explicit experiential knowledge. The villagers of Reaksmei Songha had, in many regards, the opposite problem. The bones they encountered constituted embodied evidence of events and conditions that had occurred within many residents' living memory.

Heonik Kwon (2006) has poignantly compared the movements of the first generation of survivors of the massacres at My Lai and Ha My as mirroring the sorrowful wandering of their ghostly kin — grieving, repeatedly displaced, and unable to come to rest. I contend that the residents of Reaksmei Songha were in many ways closely akin to this group of people. They too had experienced repeated violence and displacement. The resettlement of the area that began in the late 1990s was a desperate and determined endeavor to regain land and livelihoods, carried out in spite of settlers' fears of a host of social, material, and cosmological threats. The bones encountered in this resettlement process were almost unbearably temporally close to residents' own past and present circumstances. For the people who resettled Reaksmei Songha, survival was still a paramount concern and remained a tenuous affair after their entry to the area. For many, only the smallest of margins had separated them from the fate of the unknown dead encountered through their bones. Nearly every adult villager possessed tales of near escapes from execution or death.

This unsettling closeness to residents' experiences can also be glimpsed through the descriptions of the ghosts themselves. The ghosts of the mass graves shared the gnawing hunger experienced by the survivors of the DK era, embodying the suffering the living had endured. These hungry spirits were engaged in an unending search for food that mirrored the foraging experiences of area residents at the close of the war. Indeed, the specter of hunger continued to haunt poorer village residents. Perhaps, like in the case of neighboring Vietnam, changes in engagements with the grievous dead will emerge over time as life becomes more secure in Reaksmei Songha village. But in 2009, a period still wracked with continuing uncertainties and insecurities, it seemed that the dead, like the living, largely had to fend for themselves.

\section{Acknowledgments}

This research was generously supported by several research awards from the University of Edinburgh and a fieldwork grant from the Center for Khmer Studies. 


\section{List of References}

Ang, Choulean. 1986. Les etres surnaturels dans la religion populaire Khmere [The supernatural beings in the Khmer religion]. Paris: CEDORECK.

Ballard, Chris. 2002. "The Signature of Terror: Violence, Memory and Landscape at Freeport." In Inscribed Landscapes: Marking and Making Place, eds. Bruno David and Meredith Wilson, 13-26. Honolulu: University of Hawai i Press.

Cougill, Wynne. 2007. "Remains of the Dead: Buddhist Tradition, Evidence and Memory." In Night of the Khmer Rouge: Genocide and Justice in Cambodia, eds. Jorge Daniel Veneciano and Alexander Hinton, 32-47. Newark: Rutgers, State University of New Jersey, Paul Robeson Gallery.

Davis, Erik. 2008. "Between Forests and Families: A Remembered Past Life.” In People of Virtue: Reconfiguring Religion, Power and Moral Order in Cambodia Today, eds. Alexandra Kent and David Chandler, 128-44. Copenhagen: Niaspress.

- 2016. Deathpower: Buddhism's Ritual Imagination in Cambodia. New York: Columbia University Press.

Dománska, Ewa. 2005. "Towards the Archaeontology of the Dead Body." Rethinking History 9(4):389-413.

Ebihara, May. 1971. "Svay, a Khmer Village in Cambodia.” PhD diss., Columbia University.

Edwards, Penny. 2008. "Between a Song and a Prei: Tracking Cambodian History and Cosmology Through the Forest." In At the Edge of the Forest: Essays on Cambodia, History, and Narrative in Honor of David Chandler, eds. Anne Ruth Hansen and Judy Ledgerwood, 37-162. Ithaca, N.Y.: Cornell University, Southeast Asia Program Publications.

Filippucci, Paola. 2004. "Memory and Marginality: Remembrance of War in Argonne (France)." In Memory, Politics and Religion: The Past Meets the Present in Europe, eds. Frances Pine, Deema Kaneff, and Haldis Haukanes, 35-58. Munster: Lit Verlag.

Filippucci, Paola, John Harries, Joost Fontein, and Cara Krmpotich. 2012. "Encountering the Past: Unearthing Remnants of Humans in Archaeology and Anthropology." In Archaeology and Anthropology: Past, Present and Future, ed. David Shankland, 197-218. Bristol: Berg.

Fontein, Joost. 2010. "Between Tortured Bodies and Resurfacing Bones: The Politics of the Dead in Zimbabwe." Journal of Material Culture 15(4):423-48.

—. 2011. "Graves, Ruins, and Belonging: Towards an Anthropology of Proximity." Journal of the Royal Anthropological Institute 17(4):706-27.

Gouillou, Anne Yvonne. 2012. “An Alternative Memory of the Khmer Rouge Genocide: The Dead of the Mass Graves and the Land Guardian Spirits [neak ta]." In "Life after Collective Death in South East Asia: Part 1 - The (Re-)Fabrication of Social Bonds," eds. Anne Yvonne Guillou and Silvia Vignato, South East Asia Research 20(2):207-26.

Gustafsson, Mai Lan. 2007. "The Living and the Lost: War and Possession in Vietnam." Anthropology of Consciousness 18(2):56-73.

Hallam, Elizabeth. 2010. “Articulating Bones: An Epilogue.” Journal of Material Culture 15(4):465-92.

Harries, John. 2010. "Of Bleeding Skulls and the Postcolonial Uncanny: Bones and the Presence of Nonosabasut and Demasduit." Journal of Material Culture 15(4): 403-21. 
Harris, Ian. 2005. Cambodian Buddhism: History and Practice. Honolulu: University of Hawaíi Press.

Him, Chanrithy. 2000. When Broken Glass Floats: Growing Up under the Khmer Rouge, a Memoir. London: Norton.

Himm, Sokreaksa S. 2003. The Tears of My Soul. London: Monarch Books.

Hinton, Alexander. 1998. "A Head for an Eye: Revenge in the Cambodian Genocide." American Ethnologist 25(3):352-77.

— 2005. Why Did They Kill?: Cambodia in the Shadow of Genocide. Berkeley: University of California Press.

—. 2008. "Truth, Representation, and the Politics of Memory after Genocide." In People of Virtue: Reconfiguring Religion, Power and Moral Order in Cambodia Today, eds. Alexandra Kent and David Chandler, 62-81. Copenhagen: Niaspress.

Hughes, Rachel. 2006. "Memory and Sovereignty in Post-1979 Cambodia: Choeung Ek and Local Genocide Memorials." In Genocide in Cambodia and Rwanda: New Perspectives, ed. Susan Cook, 257-79. New Brunswick, N.J.: Transaction Publishers.

Krmpotich, Cara, Joost Fontein, and John Harries. 2010. "The Substance of Bones: The Emotive Materiality and the Affective Presence of Human Remains." Journal of Material Culture 15(4):371-84.

Kwon, Heonik. 2006. After the Massacre: Commemoration and Consolation in $\mathrm{Ha} \mathrm{My}$ and My Lai. Berkeley: University of California Press.

—. 2008. Ghosts of War in Vietnam. Cambridge: Cambridge University Press.

Ledgerwood, Judy. 1997. "The Cambodian Tuol Sleng Museum of Genocidal Crimes: National Narrative.” Museum Anthropology 21(1):82-98.

Locard, Henri. 2004. Pol Pot's Little Red Book: The Sayings of Angkar. Chiang Mai: Silkworm.

Ly, Boreth. 2003. "Devastated Vision(s): The Khmer Rouge Scopic Regime in Cambodia." Art Journal 62(1):66-81.

Marouda, Marina. 2008. "Lives Intimately Connected: The Living and the Dead in Contemporary Central Viet Nam." PhD diss., University of Edinburgh.

Marston, John. 2006. "Death, Memory and Building: The Non-cremation of a Cambodian Monk." Journal of Southeast Asian Studies 37(3):491-505.

Mueggler, Erik. 2001. The Age of Wild Ghosts: Memory, Violence, and Place in Southwest China. Berkeley: University of California Press.

Pin, Yathay. 1987. Stay Alive, My Son. New York: Touchstone.

Ponchaud, Francois. 1989. "Social Change in the Vortex of Revolution." In Cambodia 1975-1978: Rendezvous with Death, ed. Karl D. Jackson, 151-77. Princeton, N.J.: Princeton University Press.

Renshaw, LaYla. 2010. "The Scientific and Affective Identification of Republican Civilian Victims from the Spanish Civil War.” Journal of Material Culture 15(4):449-63.

Someth May. 1986. Cambodian Witness: The Autobiography of Someth May. New York: Random House.

Zucker, Eve. 2013. Forest of Struggle: Moralities of Remembrance in Upland Cambodia. Honolulu: University of Hawaii i Press. 